\title{
Competitive Intelligence Management in Integration and Expansion of Automobile Aftermarket Fast Repair Chain Enterprise
}

\author{
Xiaoli Wei \\ Library \\ Shanghai University of Science Engineering \\ Shanghai, China \\ Yiming Mi \\ Library \\ Shanghai University of Science Engineering \\ Shanghai, China
}

\author{
Yanfeng Xing * \\ Automotive Engineering College \\ Shanghai University of Science Engineering \\ Shanghai, China \\ Aili Geng \\ Library \\ Shanghai University of Science Engineering \\ Shanghai, China
}

\begin{abstract}
The current automobile aftermarket of China is developing with a high speed, while the integration and expansion of chain enterprises are becoming more and more serious. This paper starts from the present situation of Chinese automobile aftermarket; analyzes the demand of competitive intelligence of chain enterprises during the integration and expansion process; put forward that during the integration and expansion process, chain enterprises of Chinese after-service market should focus on the establishment of competitive intelligence system, the competition and cooperative partnership, and the monitoring of the supply chain and groups.
\end{abstract}

Keywords-competitive intelligence; chain; automobile aftermarket; integration and expansion

\section{CURRENT STATUS OF AUTOMOBILE AFTERMARKET}

The continuous climbing of car sales leads to a blowout of car ownership in China. From the sales number of 85 million vehicles in 2010 to about 180 million vehicles in 2016, Chinese auto aftermarket has attracted worldwide attention. As far as output value is concerned, the car market of 2016 is 880 billion; it is estimated to reach RMB1 trillion or more in 2017.

The industrial chain of automobile aftermarket is very long, which mainly includes three aspects: car maintenance, car finance and car replacement. Car maintenance includes repair, parts replacement, car washing, beauty, maintenance, modification, auto accessories and etc. Automobile aftermarket is ever a traditional industry with 4S shops and road shops as main former form of business. While in the recent 10 years, with huge profits cake formed by Chinese increased car ownership and increased vehicle age, and all the attendant capital influx since 2010, car aftermarket is gradually becoming the focus of attention. In form, besides the $4 \mathrm{~S}$ shops and road shops, lots of maintenance chain enterprises emerge, and the share is rapidly upgrading. Such as Car Home, Yellow Hat, New Focus, BOSCH, Little Thumb, the way

This work was supported by University Library Consortia in the Yangtze River Delta in 2017 -- Library and information fund (2017B018)
Tiger car, and other chain enterprises, including online businesses. Correspondingly, the number of professional accessories chain service providers also increased, such as Kang Zhong, Zhong Chi, and so on.

Many industry insiders believe that the development of Chinese auto industry ever dominated by auto sales has gradually been taken the lead by the automobile aftermarket, which can be found from some major auto sales and consuming countries such as USA and Japan. However, Chinese automobile aftermarket is still in the early stages of growth, its internal and external environment change rapidly and fiercely. Chinese private vehicles ages are young generally; according to the automotive industry data released in "Chinese vehicle age distribution status" magazine by DataEye \& Yuan Zheng technology, as of July 2016, the average age of China passenger car at present is 3.3 years old, the higher first-tier cities was 3.6 years. However, private vehicles will generally usher in the peak of maintenance at about 6 years old, then one hand, the automotive aftermarket enterprises are facing enormous opportunities; but due to immature market and lack of experience and, the current situation is not optimistic, the main situation is as follows:

a) The laws and regulations of Chinese auto aftermarket are not perfect yet, and they are in the process of exploration.

b) The foundation of auto aftermarket is relatively weak, and the main development is from the last 10 years, which leads to the insufficient service capacity of auto aftermarket

c) No leading enterprises, mostly small-scale, chaotic management, intelligence awareness is not strong.

d) Most of the upstream parts, oil products and maintenance products are monopolized by foreign investors

e) The current owners chose the 45 shop first. The approval of independent chain enterlprises is to be further improved 
In such occasions, it is expected to come into the process with increasingly fierce fighting, large-scale reshuffle, integration, merger and expansion. This process has already began to emerge, some enterprises ever favored by capital collapsed, some enterprises such as Japan giants ord Barkis was forced to change the business model In Chinese market. In this process, innovation, transformation, cooperation and timing is very important. Thus, besides the enterprise own strategic positioning, the competitive intelligence management concerning the market forces change and competitors is also particularly critical.

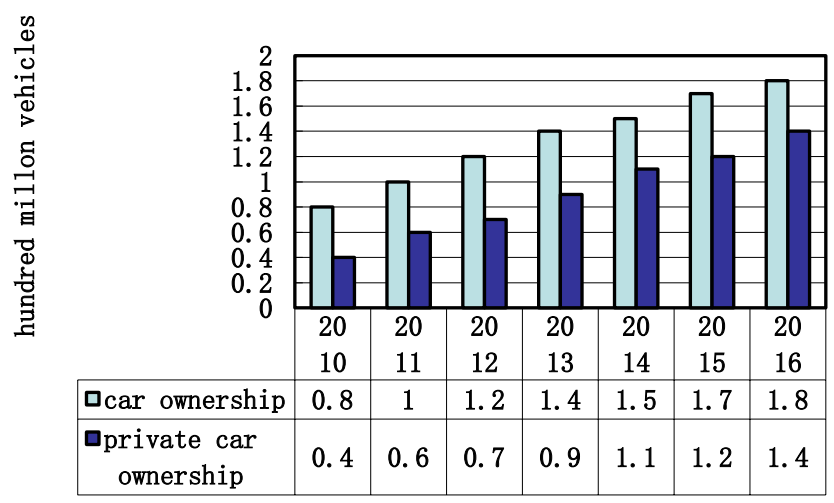

Years

\section{Qcar ownership $\quad$ aprivate car ownership}

Fig. 1. Car and private car ownership of China from 2010 to 2016

\section{THE THEORETICAL FOUNDATION OF COMPETITIVE \\ INTELLIGENCE MANAGEMENT IN THE INTEGRATION AND \\ EXPANSION OF AUTO AFTERMARKET CHAIN INDUSTRY}

Chain operation is the most active and potential management in the commercial field. The auto aftermarket maintenance chain refers to the aftermarket enterprises sold with one or more (varieties) of the goods or provide the same service in the same way, in the same price with the same brand, the same form of shops ${ }^{[1]}$. Although the chain enterprise is a whole composed of various stores, but the optimal allocation and optimal management can realize only through centralized operation and standardized management of resources, so that logistics, business flow, capital flow and information flow can constitute a huge network system. Only when the information flow is active and unblocked in the network, distribution centers, the business activities of chain stores and various departments of the headquarters can link effectively and play to the whole advantage, then realize the scale benefit of chain ${ }^{[2]}$.

Competitive intelligence is the core competitiveness of enterprises, says John E. Prescott, founder of the American Institute of competitive intelligence and professor of business at University of Pittsburgh. With a specific enterprise as oriented object, enterprise competitive intelligence is the knowledge integration collected timely, valuably and to the point, which is to meet the strategic needs of enterprises, planning or strategy. Changhuo Bao believed that the competitive intelligence was information analysis and research on competitors, competitive environment and competitive strategy, through the competitive intelligence system (CIS) to achieve, the emergence of competitive intelligence system is an important symbol which means maturity and modernization of competitive intelligence ${ }^{[3]}$; and the competitive intelligence system was a man-machine combination of competitive strategic decision-making support and consultation system, which took human intelligence as the leading, information network as a means to enhance the competitiveness of enterprises as the goal ${ }^{[4]}$. Competitive intelligence was not a single product, but a cycle model including planning and orientation, information collection, human relations, information analysis, processing, diffusion and diffusion ${ }^{[5]}$. Bolin Hua and Guangjian Li put forward that in the new environment with big data, competitive intelligence was referred to not only the fusion of multi-source information, but also the fusion of multi-level, such as analysis method ${ }^{[6]}$.

The domestic discussion on the automobile aftermarket started late. In CNKI (image 2013-2014), from 1980 to 2014, entitled "auto aftermarket" as search words, there are 1119 papers including 1056 papers since 2005, 892 papers from 2010 to 2014. This can also be seen the heat of discussion in aftermarket since 2010 with the increase of car age and ownership amount. However, most of the 892 articles after 2010 are devoted to the aftermarket pattern, trends, significance, technology and other areas, with little attention to enterprise competitive intelligence. This paper starts from the present situation of Chinese automobile after market; analyzes the demand of competitive intelligence of chain enterprises during the integration and expansion process; put forward that during the integration and expansion process, chain enterprises of Chinese after-service market should focus on the establishment of competitive intelligence system, the competition and cooperative partnership, and the monitoring of the supply chain and groups.

\section{THE COMPETITIVE INTELLIGENCE MANAGEMENT IN INTEGRATION AND EXPANSION OF AUTO AFTERMARKET CHAIN ENTERPRISES}

\section{A. The current status of competitive intelligence management of auto aftermarket}

The current auto aftermarket of China is facing the integration and expansion of the industry. The adaptable survivals will usher in the next great development, while those who are not suitable will be eliminated. The integration of intelligence management in the expansion is a dynamic, continuous, relatively more complicated process. It is not only related to the industry information management, information management also involves the cross-border import. As the intelligence content management is more variable, the collection, analysis and strategy forming should be updated timely, which has greater requirements on the output and configuration than the steady state. However, although the current automotive aftermarket intelligence management gets more and more attention, it still can't keep up with the requirements of development. The present situation is as follows:

- Enterprise executives are gradually aware of the importance of competitive intelligence, while 
employees are generally conscious of indifference and even unconsciousness. The consciousness is top-down; although the management is keen on the industry information communication, but this awareness has not passed to the underlying and middle-level staff.

- The collection and analysis of enterprise competitive intelligence is unsystematic, and most of them are still in the initial stage. The information collection of some enterprises and even chain of enterprise, still rely on personal brain of the core staff or simple EXCEL forms and other primitive tools. Some cross-border or ambitious chains began to invest in information systems, such as ERP, CR, OA, store management system and other information collection system to sort out and trace the market dynamics. But the investment is mostly in the beginning, and most of them are on the internal supply chain and customer business information collection, which do not form a complete system of competitive intelligence collection.

- $\quad$ Rather than relying on the acquisition of interpersonal information, and ignoring the technical means of analysis and arrangement. Some of the industry chain enterprises pay more attention to the rally, occupation school, peer communication, but limit in the analysis of the information obtained, so the information is often confined to the participant or small scale of people.

\section{B. The meaning of competitive intelligence management in} integration and expansion

The integration of the expansion involves lots of work on market dynamics, political policy, new products, new technology and other aspects of the information processing. Adding intelligence management in the process, there are following meanings:

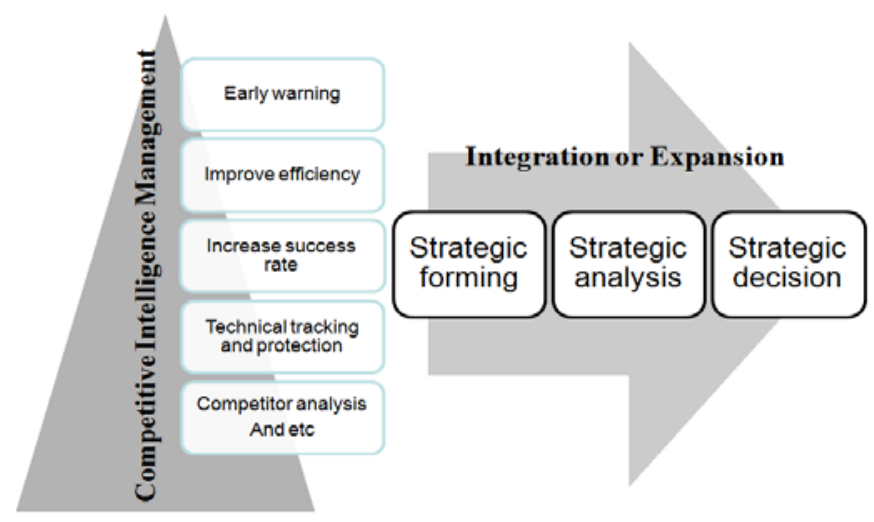

Fig. 2. The meaning of Competitive Intelligence Management

- Early warning: the perception of environmental policy and changes of the market can help to predict the changes brought about by the business opportunities or threats; combined with the enterprise's internal environment, so as to prepare for the enterprise expansion, consolidation or other decision.
- Improving the efficiency of enterprise integration or expansion: through timely search, analysis and processing of the new technology and the competition information can provide timely information to support the formulation and implementation of the management of the company's decision, so as to improve the efficiency of integration or expansion of the company in a rapidly changing market.

- Improving the success rate of strategic decision: timely and accurate information can make up for the information asymmetry in the integration or expansion, which can largely avoid the blindness and uncertainty, so as to improve the success rate of strategic decision.

C. Core competence of chain enterprises of auto aftermarket in integration and expansion

The success rate in the current integration and expansion is not high. Car home known as driving to 10000 stores in 5years, but not only the speed of opening stores is far from keeping pace with it, and the blind expansion of the stores in the process led to unprofitable, or even losses. Autobacs closed Chinese terminal stores in the past few years and adjusted the previous strategies to be a supplier to the terminal. Some enterprises ever as the media star and models of the industry, suddenly declared bankruptcy. How to maintain the core competitiveness in cross-border competition , integration and expansion of the industry, the core competitiveness is as follows through the communication with more than 10 enterprises:

a) The investment and financing ability of enterprises: Nowadays, the auto aftermarket is the focus of capital, and it can play the important role in the rapid expansion of enterprises at the right time. However, it is not the more capital entering, the better for enterprises. The excessive dependence on capital cannot fundamentally improve the competitiveness of enterprises. Therefore, the identification of capital and the injection of capital are crucial to the enterprise.

b) Chain store location: It is the key to the auto aftermarket. A good store location can lead to a 50\% store success rate, therefore the enterprise must have mature location team and location program to support.

c) Ability to integrate and expand the chain: whether the chain enterprises to integrate the other companies, or partnership or merger, or to carry out self expansion, a mature evaluation mechanism, a series of deliberate integration process, a set of new stores startup process, as well as mature negotiation skills and culture are very important.

d) Supply chain integration capability: with red sea strategy for almost all domestic industries, the ability of supply chain integration ability of auto aftermarket is critical. At present, it can even say that the supply chain will have the world. A mature and excellent supply chain system will enable enterprises to have cost advantages and quality advantages.

e) The information level of the enterprises: enterprise's information level determines the scale of the enterprise. The 
chain must force through the popularity of information. It is the only way to maintain consistency and order of the operation and management of enterprises in different stores. The popular information software in auto aftermarket includes store management system, OA system, ERP, CRM and so on.

f) Enterprise operation and management ability: Store operation is the source of enterprise income. Therefore, enterprise operation and management, including store display, promotion, sales, service, and technology and so on, is always the enterprise focus.

D. The main content of intelligence management for auto aftermarket in integration and expansion

- Establish competitive intelligence system for information management and manage with professional and technical means. Change the previous fragmentation of the original competitive intelligence collection and analysis method, set the hand even department of competitive intelligence management. At the same time, use the computer as the main processing means and network cloud as one of the main tools for information storage.

- Continue to play the role of human intelligence network, but need to be supplemented by technical means of timely treatment and processing of the acquired information.

- $\quad$ Take the monitoring of competitors, supply chain and government policies as the main monitoring direction.
Establish information network of competitors and supply chain system, and pay close attention to their dynamics and analysis in a timely manner. For auto aftermarket, the government's policy changes have shown signs of accelerating in the near future; with reference to foreign history, there will be conducive to the development of the aftermarket. And the policy changes, largely will have a significant impact on the pattern of the industry.

\section{REFERENCES}

[1] Jifang Wang. Chain management tutorial. Beijing: Chinese economic press, Jan 2005 (In Chinese).

[2] Meng Li. "Research on informatization and core competence of retail chain enterprises,” Master's degree thesis of China Institute of science and technology information, 2005(In Chinese).

[3] Changhuo Bao, Ying Huang, Gang Zhao, "Research on developing competitive intelligence system,” New Technology of Library and Information Service, 2004(1), pp76-80 (In Chinese).

[4] Changhuo Bao, Xinzhou Xie, Yan Zhang, Na Li, “Enterprise competitive intelligence system,” vol.8. China information, 2001(8), pp33-36 (In Chinese).

[5] Herring JP. "Key intelligence topics: a process to identify and define intelligence needs,” vol. 2. Competitive intelligence Review. October 1999, pp4-14

[6] Bolin Hua, Guangjian Li, "Multi-source fusion competitive intelligence research in big data environment," vol. 38, Information studies: Theory \& Application, 2015(4), pp.1-5 (In Chinese). 